$$
\text { DOE } / \text { JLR / } 40150-1200
$$

\title{
Exposure of GaAs to Atomic Hydrogen for Cleaning Prior to NEA Photocathode Activation
}

\author{
C. K. Sinclair, B. M. Poelker, J. S. Price
}

Jefferson Lab, 12000 Jefferson Avenue, Newport News, VA 23606 USA P $\mathrm{CP}$ C

NOV 121997

INTRODUCTION

Creating an atomically clean semiconductor surface is an essential step in preparing negative electron affinity (NEA) photoemission cathodes [1]. While bulk GaAs can be satisfactorily cleaned by chemical etching and in situ heat cleaning, many high polarization electron source materials are either much too thin, or have oxides and carbides which are too tightly bound, to be cleaned by these methods. Some polarized source candidate materials may be degraded during the heat cleaning step.

It is well established that the exposure of many III-V, II-VI, and elemental semiconductors to atomic hydrogen, typically at elevated temperatures, produces semiconductor surfaces free of contamination. Furthermore, this cleaning, possibly followed by thermal annealing, leaves surfaces which show sharp LEED patterns, indicating good stoichiometry and surface order [2]. Atomic hydrogen cleaning should eliminate the chemical etching step, and might reduce the temperature and/or temperature-time product presently used in forming NEA cathodes. The process is readily adaptable to in situ use in ultrahigh vaccum.

\section{EXPERIMENTAL APPARATUS AND PROCEDURES}

We constructed a small $250^{\circ} \mathrm{C}$ bakeable ultrahigh vacuum chamber for this work. After initial bakeout, pressures below $10^{-8}$ mbar were reached within hours after the introduction of a new sample. At these pressures, it is feasible to conduct cleaning and photoresponse experiments without bakeout. We did not fabricate NEA cathodes in the unbaked chamber, but did measure the photoresponse to cesium. In all our measurements, a large photoresponse to cesium in the unbaked chamber correlates very well with the subsequent post bakeout formation of a high quantum yield NEA cathode. Elimination of the bakeout step allowed relatively rapid progress. All experiments reported here used bulk GaAs samples p-doped at 2.7 to $5.4 \times 10^{18} / \mathrm{cm}^{3}$.

Following initial experiments with DC hydrogen glow discharges, which showed clear evidence of cleaning in some circumstances, we decided to develop an RF dissociation atomic hydrogen source. This source, a modification of one developed as a polarized atomic hydrogen source, employs a helical resonator surrounding a $2.5 \mathrm{~cm}$ diameter pyrex tube which contains the hydrogen glow [3]. Hydrogen is admitted through an ultrahigh vacuum leak valve. Atomic hydrogen exits the glow 


\section{DISCLAIMER}

This report was prepared as an account of work sponsored by an agency of the United States Government. Neither the United States Government nor any agency thereof, nor any of their employees, make any warranty, express or implied, or assumes any legal liability or responsibility for the accuracy, completeness, or usefulness of any information, apparatus, product, or process disclosed, or represents that its use would not infringe privately owned rights. Reference herein to any specific commercial product, process, or service by trade name, trademark, manufacturer, or otherwise does not necessarily constitute or imply its endorsement, recommendation, or favoring by the United States Government or any agency thereof. The views and opinions of authors expressed herein do not necessarily state or reflect those of the United States Government or any agency thereof. 


\section{DISCLAMIER}

Portions of this docoment may be illegible in electronic imoge products. Imsges are produced from the best available original document 
through a $1 \mathrm{~mm}$ aperture, and is conducted to the the sample by an aluminum tube, which has a low atomic hydrogen recombination coefficient. The resonator is stainless steel, permitting it to be baked.

Much molecular hydrogen enters the vacuum chamber during cleaning, requiring a high hydrogen pumping speed. This is provided by a $30 \mathrm{l} / \mathrm{s}$ DI pump and a $220 \mathrm{l} / \mathrm{s}$ non-evaporable getter. Dissociation occurs over a broad range of hydrogen pressure and RF frequency. It is necessary to consider recombination as well as dissociation fraction to obtain the optimum conditions for cleaning. We found that low hydrogen pressure (18-20 mTorr) and 116-118 MHz RF gave the best results in our apparatus. We estimate the atomic hydrogen flux to the sample was approximately $10^{17} / \mathrm{cm}^{2} / \mathrm{s}$. A cleaning time of 30 minutes was adequate to obtain high quantum yields. The sample is held at $300^{\circ} \mathrm{C}$ during cleaning, followed by 10 minutes at $450^{\circ} \mathrm{C}$ to desorb hydrogen.

\section{RESULTS AND CONCLUSIONS}

All parameters were optimized with the cesium-only photoresponse method in the unbaked chamber. Following an initial test with a chemically etched sample in a baked chamber, we installed a GaAs sample which had been degreased only and again baked the chamber. After atomic hydrogen cleaning and a heat cleaning cycle we prepared a photocathode by activation with cesium and $\mathrm{NF}_{3}$. The quantum yield as a function of wavelength for this cathode is shown in figure 1 . The discontinuity at approximately $790 \mathrm{~nm}$ is a result of our not yet normalizing the curves above and below this wavelength properly. Our optical source is a grating spectrometer with a short arc xenon lamp. At the wavelength of the discontinuity, we inserted a $715 \mathrm{~nm}$ low pass filter to remove second order reflections. The long wavelength data are complicated by two very strong xenon lines in this region. We normalized the short wavelength spectrum by a diode laser measurement at $670 \mathrm{~nm}$, and the long wavelength spectrum by a diode laser at $789 \mathrm{~nm}$, but residual normalization problems remain. However, we clearly have a very good quantum yield throughout the wavelength range of interest for $\mathrm{GaAs}$ polarized sources.

One might expect that cathodes activated with oxygen may differ near the bandgap from those activated with fluorine. NEA activation with molecular oxygen is difficult to control in our experience, leading us to try nitrous oxide. We heat cleaned the $\mathrm{NF}_{3}$ cathode of figure 1 and reactivated using $\mathrm{N}_{2} \mathrm{O}$. This result is also shown in figure $1 . \mathrm{N}_{2} \mathrm{O}$ activation is clearly promising. Both cathodes showed $1 / \mathrm{e}$ lifetimes of about 1000 hours under continuous $789 \mathrm{~nm}$ diode laser illumination.

In summary, we have demonstrated that GaAs wafers can be cleaned for NEA activation by in situ exposure to atomic hydrogen, with no previous chemical cleaning. We believe this cleaning will perform equally well on thin strained or multilayer samples, and on alloys containing aluminum or silicon, for which chemical cleaning either cannot be employed, or is not successful. The use of $\mathrm{N}_{2} \mathrm{O}$ as an oxygen source for NEA activation was also demonstrated. 


\section{ACKNOWLEDGEMENTS}

This work began in collaboration with Bruce Dunham at the University of Illinois. Khaled El-Amrawi and Dr. Hani Elsayed-Ali, of Old Dominion University, participated in a portion of this work. Prof. Roy Holt of the University of Illinois provided support for the pyrex glassblowing. This work was supported by the USDOE under contract DE-AC05-84ER40150.

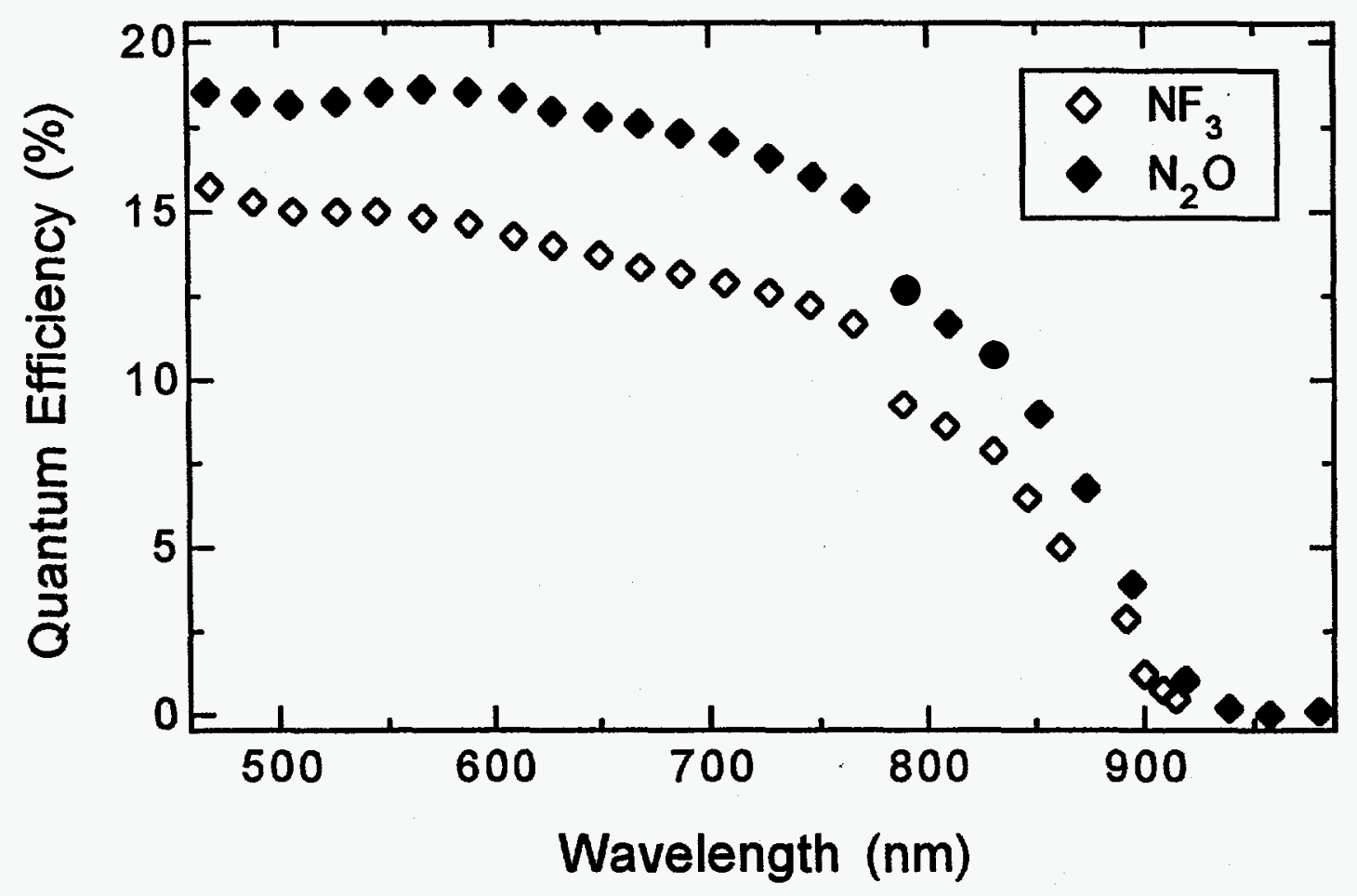

Figure 1. Quantum efficiency versus wavelength for atomic hydrogen cleaned bulk GaAs, activated with cesium and $\mathrm{NF}_{3}$ or cesium and $\mathrm{N}_{2} \mathrm{O}$.

[1] J. J. Uebbing, J. Appl. Phys. 41, 802 (1970); J. S. Escher in "Semiconductors and Semimetals", v. 15, Academic Press, N.Y., 1981, p.195.

[2] There is very extensive literature on this topic, primarily directed to device applications. Recent examples include: Y. Luo et al, Appl. Phys. Lett. 67, 55 (1995); Y. Okada and J. S. Harris, J. Vac. Sci. Technol. B14, 1725 (1996); Z. Yu et al, Appl. Phys. Lett. 69, 82 (1996).

[3] M. Poelker et al, Nucl. Instr. Meth. A364, 58 (1995). 